\title{
Epithelioid trophoblastic tumor
}

INSERM

\section{Source}

INSERM. (1999). Orphanet: an online rare disease and orphan drug data base. Epithelioid trophoblastic tumor. ORPHA:254698

An epithelioid trophoblastic tumor is an extremely rare gestational trophoblastic tumor (GTT; see this term) which generally occurs several years after pregnancy. 